\title{
A New Species of Pennsylvanian Plant Fossil (Cyclopteris N.Sp.) from the Placid Shale Member, Brad Formation, Near Ranger, Eastland County, Texas
}

\section{Ryan F Morgan ${ }^{1 *}$, Kris L Juntunen ${ }^{1}$ and Ashley Scott ${ }^{2}$}

${ }^{1}$ Department of Chemistry, Geosciences and Physics, Tarleton State University, USA

${ }^{2}$ Department of Geological and Environmental Sciences, Western Michigan University, USA

*Corresponding author: Ryan F Morgan, Department of Chemistry, Geosciences, and Physics, Tarleton State University, Stephenville, Texas, 76401, USA, Tel: 254-968-9894; Email:

\section{Research Article}

Volume 3 Issue 1

Received Date: October 06, 2020

Published Date: November 16, 2020

rmorgan@tarleton.edu

\section{Abstract}

A new species of Cyclopteris sensu was discovered in the upper sandstone beds of the Placid Shale. New species is distinguished by chevronate veins present between major radiating veins characteristic of Cyclopteris. Discovery of this species expands this genus into the Carboniferous delta deposits of Central Texas, and demonstrates the need to revisit these classic sites.

Keywords: Plant Fossil; Taxonomy; Species

\section{Introduction}

Fossilized plant material is characteristic of the late Paleozoic, and common throughout the exposures in north Central Texas [1,2]. Despite the commonality of fossil material, most sites are underworked, and lack formal description of the stratigraphy, the contained fossils, or more often, both. This study contributes a small part to this, by including both formal description of the fossil material, albeit fragmentary, and the stratigraphy of the containing bed.

Descriptions from fragmentary and partial fossil material are increasingly rare, but are important to cataloguing important sites and morphologies. Many fossil plant genera and species are described from partial fossils, prompting further research and improvement of our understanding of plant taxonomy and evolution.

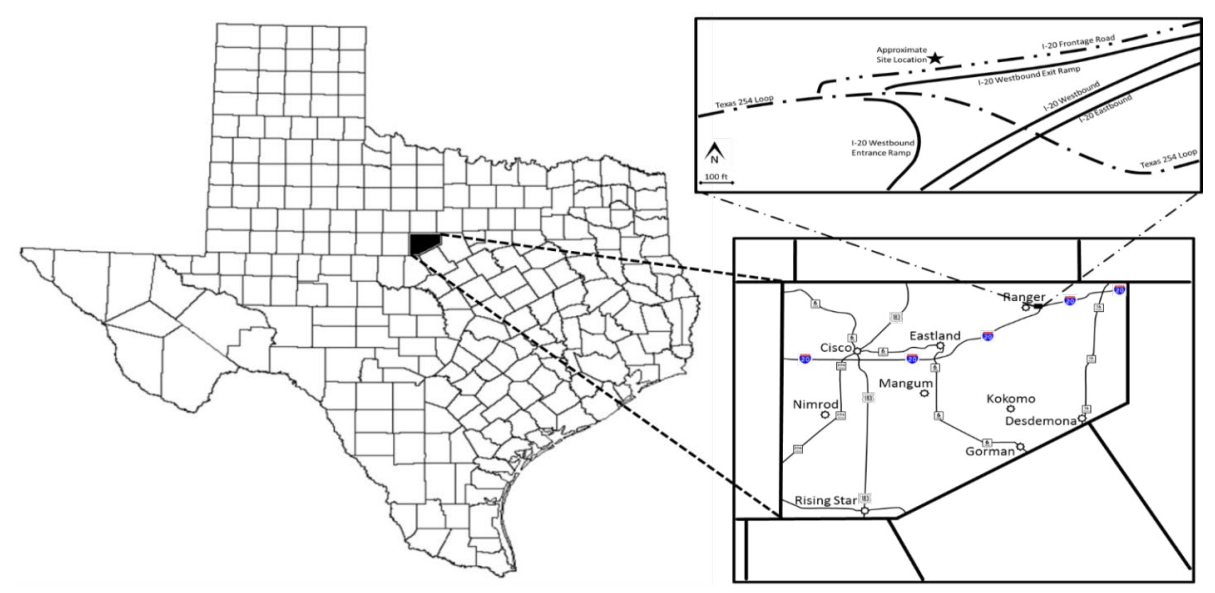

Figure 1: State, country, and local inset maps for the study location. Star indicates approximate study locality in upper right inset. 


\section{International Journal of Paleobiology \& Paleontology}

The collection of sampled intervals from the Placid Shale Member of the Brad Formation are located in outcrop along west bound I- 20 frontage road, roughly 0.2 miles east of the intersection with Texas 254 Loop in Ranger, Texas (Figure 1 ). The outcrop is situated on the north side of the frontage road, with about 35 feet of relief. Initial presentation is tan to buff sands with loose and slumped blocks of limestone and sandstone strewn across. Small mountain cedars and mesquite obscure parts of the outcrop. A barbed wire fence runs the breadth of the outcrop, and prevents access to the overlying sands of what is presumably disconformably laid Cretaceous-age Antlers Formation [3]. Importance is placed on this particular exposure, acting as a reference section for possible comparison to other plant species similar to Cyclopteris n.sp.

\section{Body of Paper}

\section{Geologic Setting}

The examined outcrop is identified as an exposure of the Brad Formation of the Canyon group. The Brad formation is underlain by the Palo Pinto and Graford Formations, and overlain by the Caddo Creek formation, although the Caddo creek is absent locally [4]. The Brad formation contains two members: the Placid Shale and the Ranger Limestone. The Placid Shale has been described as ranging from 30 to 50 feet thick, containing primarily shales and sandstone lenses [5]. Historically, the lowermost part of the Placid Shale as described contained significant limestone beds [6], but these are now considered part of the underlying Graford Formation. Alternatively, the Placid Shale has been known as the Seaman Ranch Shale [5], particularly in the area of the Brazos River. This unit is described as 150 to 200 feet of Shale, with intermingled sands and limestones. Most stratigraphers now consider the Placid Shale and Seaman Ranch Shale members to be continuous and synonymous, with the Placid Shale taking precedence of name [7]. The Placid Shale is overlain by the massive Ranger Limestone, described as very cherty, ranging from 10 to 50 feet thick [5]. The Ranger Limestone member first appears just east of Ranger, Eastland County, Texas, and thickens westward, where erosion into the resistant cherty limestone produces high bluffs and hills [4].

Both the Placid Shale and the Ranger Limestone members have been interpreted as evidence of successive drowning of coastal river delta systems, with steady transgressive episodes coming from the west. Crossbedding, channeling, and detrital sediments ranging from fine muds to conglomerates supports this coastal fluvial to marine succession, with the increased limestone production of the Ranger Limestone indicative of marine submersion (Figure 2).

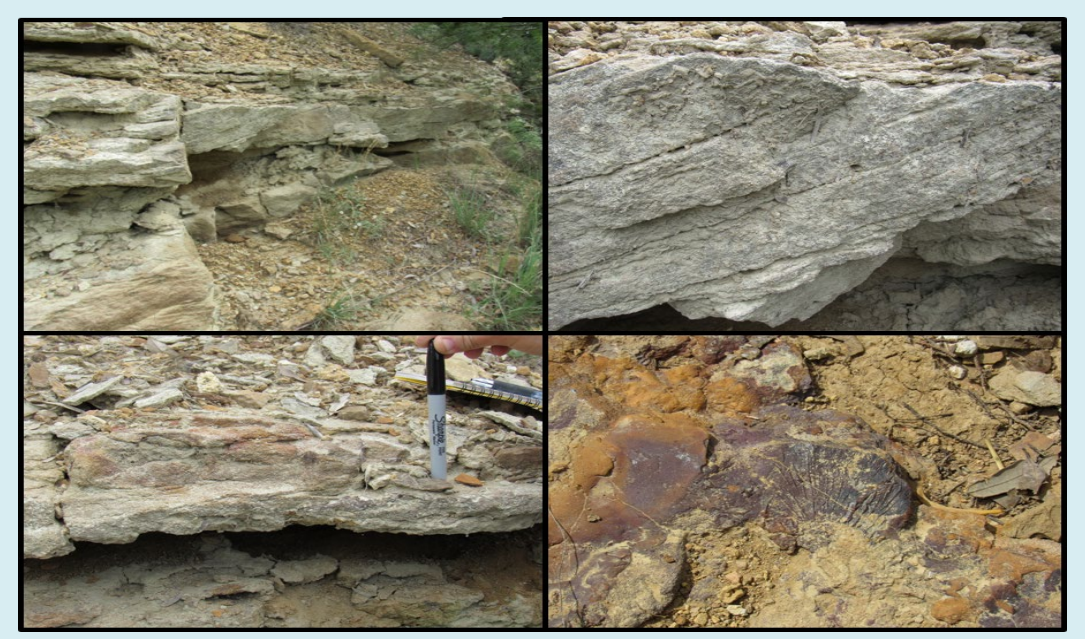

Figure 2: Field site photos from Placid Shale outcrop. Top Left) General appearance of field site, demonstrating resistant sandstone layers and more weathered shales. Top Right) Pronounced cross bedded sandstone of Unit 3. Lower Left) Cross bedded sandstone of Unit 3, demonstrating some iron oxide cements. Layers in this unit are more fine scale than the underlying Unit 2. Lower Right) Field presentation of plant fossils (Cyclopteris n.sp.) preserved in iron oxides of Unit 3.

Regionally, the locality during the Pennsylvanian is located on the coast, where detritus from the nearby Oachita Mountains which arose during the Laurasian collision with Gondwana erode westward into the Central Texas basins. During time of deposition, North-central Texas was equatorially located, where moist lowlands and river drainage would have provided ideal environments for seed fern and other lowland plant species. 


\section{International Journal of Paleobiology \& Paleontology}

\section{Stratigraphic Description}

Outcrop measurements were collected with the use of a Jacob's staff and Brunton compass. Differentiation of stratigraphic units is based on lithologic, structural, and fossil content. Samples from each stratigraphic unit were collect to supplement field observations and future research. No permits were required for the described study, which complied with all relevant regulations. A stratigraphic column was constructed using field and laboratory observations (Figure 3).

A general description of the site is as follows: Top of Section

5. Crossbedded medium grained sandstone. Ripples present on upper surface. Small channel structures present. Gastropods, cephalopods, crinoids, brachiopods, and solitary corals throughout. Rounded grains of carbonized plant material and intermittent lenses of lighter colored mud occur sporadically throughout. $80 \mathrm{~cm}$ 4. Interbedded grey shale and silty clay. Chert fragments and iron concretions are intermittent. Fossils absent. $430 \mathrm{~cm}$

3. Crossbedded medium grained sandstone with interbedded planar siltstone and sandstone. The sandstone fines upwards, varying from fine to very fine in the lower portion, to medium to coarse in the upper portion of the unit. Crossbedding is pronounced and in the same NW dip of the underlying units. The upper portion of unit three contains abundant plant material. The silicified wood in this unit is larger (up to 8.4 $\mathrm{cm}$ in length observed) and less fragmentary than in the lower units. One fossil leaf (Cyclopteris n.sp.) was collected from this unit. $52 \mathrm{~cm}$

2. Fine to medium-grained calcareous sand with nodular mud clasts. Ferrous nodules and petrified wood fragments throughout. Crossbeds dip toward the NW. $30 \mathrm{~cm}$ 1. Cross-bedded dominantly coarse-grained sandstone with thin carbonate mud interbeds. Numerous plant fossils and ferrous concretions within the upper $10 \mathrm{~cm}$ of the unit. Crossbedding dips to the SE. $40 \mathrm{~cm}$ Base of Section.

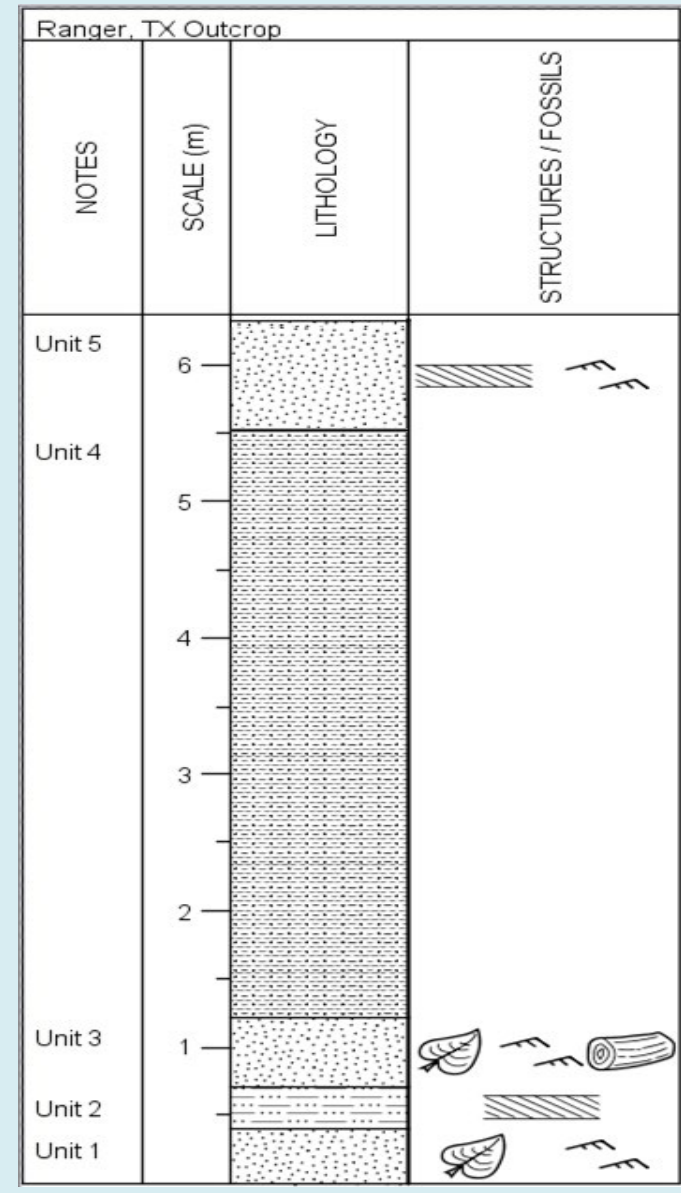

Figure 3: Stratigraphic column of the Ranger outcrop locality. Cyclopteris n.sp. is found preserved in iron oxide dominated siltstones within unit 3. Stratigraphic column generated using SedLog ver. 3.1 [8]. 


\section{International Journal of Paleobiology \& Paleontology}

\section{Nomenclatural Acts}

The electronic edition of this article conforms to the requirements of the amended International Code of Zoological Nomenclature, and hence the new names contained herein are available under that Code from the electronic edition of this article. This published work and the nomenclatural acts it contains have been registered in ZooBank, the online registration system for the ICZN. The ZooBank LSIDs (Life Science Identifiers) can be resolved and the associated information viewed through any standard web browser by appending the LSID to the prefix "http://zoobank. org/". The LSID for this publication is: urn:Isid:zoobank. org:pub:AFB9C46E-80E4-4997-8A26-F56D0852525B. The electronic edition of this work was published in a journal with an ISSN, and has been archived and is available from the following digital repositories: PubMed Central, LOCKSS. Specimens studied can be found at the following repositories: Texas Memorial Museum, University of Texas at Austin: NPL92382.

\section{Systematic Paleontology}

Kingdom Chlorobiota Kendrick, et al. Crane ( $\equiv$ Viridiplantae
Cavalier-Smith) $[9,10]$

Family Neuropteridae Dilcher, et al. [11]

Genus Cyclopteris sensu Brongniart [1]

Type species: Cyclopteris orbicularis OUMNH E.3439.

\section{Definition}

Simple, entire, orbicular or reniform frond; numerous ribs, all equal, dichotomous, radiating from the base. The form and arrangement of the ribs of the fronds of ferns are analogous to those of live ferns (e.g., Adianthum reniformes and $A$. asarifolium, and Trichomanes reniformes). The essential characteristic of this genus is to have no median ribs, all the ribs being equal and meeting at the base of the leaf [1]. This is typically interpreted as densely radiating venation on reniform to orbicular fossil leaves [12].

\section{Cyclopteris Chevronit}

new species:

urn:lsid:zoobank.org:act:CC8E70B2-FA90-4DC4-9B221588662BF9BE (Figure 4).

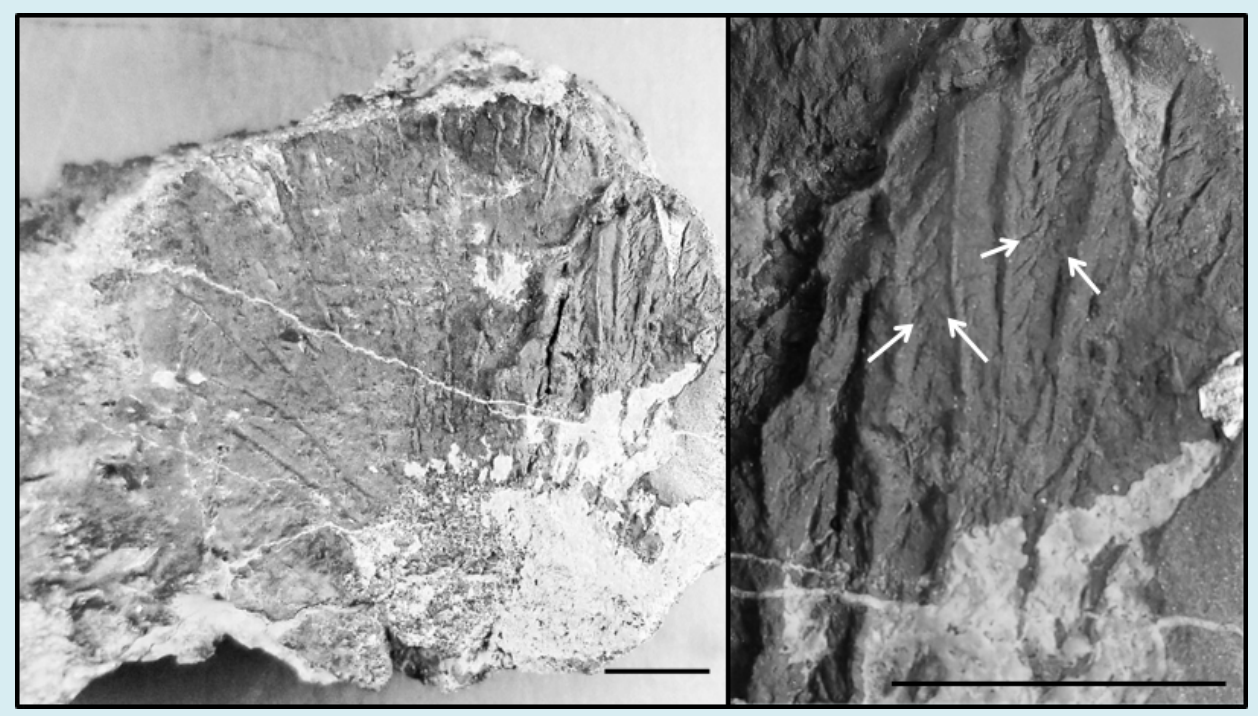

Figure 4: Staged photographs of Cyclopteris chevronii. Left) Overall view of specimen NPL92382. Scale bar = one centimeter. Right) Magnified view of Cyclopteris chevronii, scale bar = one centimeter. Arrows indicated chevronate veins along leaf structure, in-between major radiating veins.

\section{Derivation of Name}

Named for the distinct chevronate veins present between the radiating veins of the leaf.

\section{Type Specimen}

NPL92382.

\section{Diagnosis}

A single fossil leaf was recovered from Unit 5 of the Pennsylvanian deposits found exposed east of Ranger, Eastland County, Texas. Leaf is fragmentary, lacking base. Lack of material does not prevent generic diagnosis. Leaf is planate, with a small fold preserved on the right side. Shape is orbicular, with no apparent outer fringe. This leaf 


\section{International Journal of Paleobiology \& Paleontology}

demonstrates radiating venation, lacking a pronounced midrib vein. Spacing between veins is small, between 0.5 and $2 \mathrm{~mm}$. Venation between radiating vein limbs is irregular to distinctly chevronate.

\section{Discussion}

Cyclopteris chevronii is distinctive from other Cyclopteris species. Compared to the three Cyclopteris species considered legitimate [12], C. chevronii is distinct. C. orbicularis [1] is a small, entire leaflet with finely radiating venation, dissimilar from the more robust radiating veins of $C$. chevronii. C. obliqua [1], while considered a legitimate species name, lacks any type specimens or figures still in existence, and the original paper citing this name [1], does not include descriptive taxonomy. However, as this specimen was from the Upper Carboniferous of Britain, it is unlikely the same as species as $C$. chevronii. $C$. flabellata [1] specimens are neither orbicular nor reniform [12] and possess prominent petiolules, differing greatly from that of C. chevronii. Other named species of Cyclopteris (i.e., C. trichomanoides, C. germani, C. digitata, C. elegans, C. valida, C. reniformis, $C$. auriculata) are no longer conserved valid or have been reassigned to other genera [12], and are not included in this comparison.

\section{Conclusion}

Carboniferous paleontology and stratigraphy within Central Texas is still largely underworked. Describing, visiting, and revisiting many of these units and sites will aid in further understanding of these units, and help in resolving regional connections between these ecologies of southern Laurentia and those of the North American Appalachian and European deposits of similar age, as well as increase the number of known plant species from this time period. The widely exposed deposits of Carboniferous deltas throughout Central Texas are well poised to provide this insight. In addition to these previous incentives, Cyclopteris is a widespread genus, known from the Carboniferous of North America and Europe, but very little research has been done with this genus since the $19^{\text {th }}$ century, despite largely available material. The introduction of a new species may aid in stimulating this research.

\section{References}

1. Brongniart A (1828) Prodrome d'une histoire des végétaux fossils. Paris, pp: 234.

2. Mamay SH (1968) Russellites, new genus, a problematical plant from the lower Permian of Texas. USGS, pp: I1-I15.

3. Sellards EH, Adkins WS, Plummer FB (1933) The Geology of Texas. Austin, The University of Texas, pp: 1006.

4. Plummer FB (1919) Preliminary Paper on the stratigraphy of the Pennsylvanian Formations of northcentral Texas. American Association of Petroleum Geology Bulletin 3(1): 132-150.

5. Plummer FB, Moore RC (1922) Stratigraphy of the Pennsylvanian Formations of Central Texas. University of Texas Bulletin 2132(237): 19.

6. Bullard FM, Cuyler RH (1935) The Upper Pennsylvanian and Lower Permian section of the Colorado River valley, Texas. University of Texas Bulletin 3501: 191.

7. Wilmarth GM (1937) Lexicon of Geologic Names of the United States (including Alaska). USGS Bulletin 896: $1-2396$.

8. Zervas D, Nichols GJ, Hall R, Smyth HR, Lüthje C, et al. (2009) SedLog: a shareware program for drawing graphic logs and log data manipulation. Computers \& Geosciences 35(10): 2151-2159.

9. Cavalier Smith T (1981) Eukaryote Kingdoms: Seven or Nine? BioSystems 14(3-4): 461-481.

10. Kenrick P, Crane PR (1997) The Origin and Early Diversification of Land Plants: A Cladistic Study. Smithsonian Institution Press, Washington DC, pp: 441.

11. Dilcher DL, Lott TA, Axsmith BJ (2005) Fossil plants from the Union Chapel Mine, Alabama. Pennsylvanian Footprints in the Black Warrior Basin of Alabama. Alabama Paleontological Society Monograph 1: 153-168.

12. Cleal CJ, Shute CH (1998) Proposal to conserve the generic name Cyclopteris (fossil plants against Cyclopteris (non-fossil Pteridophyta). Taxon 47(2): 448-450. 